\title{
CA19-9 May Be a Prognostic Factor for Medullary Thyroid Carcinoma
}

\author{
Yasuhiro Ito and Akira Miyauchi \\ Department of Surgery, Kuma Hospital, Kobe, Japan
}

Review of: Alencar R, Kendler DB, Andrade F, Nava C, Bulzico D, de Noronha Pessoa CC, Corbo R, Vaisman F. 2019 CA19-9 as a predictor of worse clinical outcome in medullary thyroid carcinoma. Eur Thyroid J 8:186-191. PMID: 31602360.

\section{SUMMARY}

\section{Background}

It is well known that postoperative serum calcitonin and carcinoembryonic antigen (CEA) levels are important markers in patients with medullary thyroid carcinoma (MTC) to confirm biochemical cure after thyroid surgery. Miyauchi et al. have shown that postoperative calcitonin doubling-time is strongly related to the prognosis of MTC (1-3).

Carbohydrate antigen (CA) 19-9 is another useful tumor marker that has been utilized mostly during the monitoring of pancreatic tumors $(4,5)$, although it is also expressed in nonmalignant tissues of the digestive and respiratory tracts (6). Several previous studies have shown increased expression of CA19-9 in MTC tissues and the presence of elevated serum CA19-9 levels, especially in aggressive cases of MTC (7-9). However, the published literature on this topic is limited, and the mechanism of the association with MTC remains mostly unknown. The current study investigated the postoperative serum CA19-9 level in patients with MTC to investigate whether they reflect aggressive behavior and worsened prognosis (10).

\section{Methods}

This study enrolled patients with sporadic or hereditary MTC who were treated and followed by the Brazilian National Institute of Cancer between
1985 and 2017. The cohort contained 122 patients (77 females and 45 males), and the median age was 46 years (range, 12.1-87.9). After surgery, all underwent serum calcitonin and CEA monitoring. CA19-9 measurements had been started in 2015,so there were 65 patients who underwent monitoring of their postoperative CA19-9 levels. Other clinicopathological features were collected by studying medical records or by administering questionnaires. The median follow-up period was 74 months (range, 3-395). At the end of follow-up, patients' status was classified into four categories: no evidence of disease, biochemical persistent disease, structural persistent disease, and progressive disease.

\section{Results}

Following surgery, the median first postoperative CA19-9 $(\mathrm{n}=65$ ) was $7.85 \mathrm{U} / \mathrm{ml}$, the median calcitonin ( $\mathrm{n}=122$ ) was $92 \mathrm{pg} / \mathrm{ml}$, and the median CEA ( $n=122$ ) was $7.82 \mathrm{ng} / \mathrm{ml}$. At the end of follow-up, patients' statuses were classified as: no evidence of disease (33 patients [27.1\%]), biochemical persistent disease (27 [22.1\%]), structural persistent disease (22 [18.1\%]), and progressive disease (40 [32.7\%]). Disease-related death occurred in 37 patients (30.3\%).

In univariate analysis, elevated postoperative CA19-9 levels were significantly related to MTC 
progression (21.4 U/ml [range, 14.3-110.9] vs. 7.27 $\mathrm{U} / \mathrm{ml}$ (range, 0.6-44.75), $\mathrm{P}=0.01$ ) together with high postoperative CEA, patient age, tumor size, clinical node metastasis, and distant metastasis. Also, the median first postoperative level of CA19-9 was $18.43 \mathrm{U} / \mathrm{ml}$ (range, 14.3-110.9) in patients who died of disease, which was significantly higher $(P<0.001)$ than that of $7.59 \mathrm{U} / \mathrm{ml}$ in surviving patients. Patients with a first postoperative CA19-9 of $>18.3 \mathrm{U} / \mathrm{ml}$ showed a significantly poorer $(\mathrm{P}<0.0001)$ overall survival than those with CA19-9 of $\leq 18.3 \mathrm{U} / \mathrm{ml}$. Although there was a positive linear correlation between the first postoperative cal- citonin and the first postoperative CA19-9 levels ( $R 2=11.9, P=0.01)$, the doubling time of CA19-9 did not show any statistical significance for tumor progression or disease-related death.

\section{Conclusions}

Serum CA19-9 may potentially be a prognostic factor for patients with MTC, in addition to calcitonin and CEA. In this study, the cutoff for serum CA19-9 was much lower than that traditionally used for pancreatic tumors, indicating that a specific reference range should be established by future studies.

\section{COMMENTARY}

This study (10) investigated the relationships between postoperative serum CA 19-9 levels, progression of MTC, and disease prognosis. Since CA19-9 had only begun to be measured toward the end of the cohort's recruitment period, the number of patients who underwent postoperative CA 19-9 measurement was small $(n=65)$ and the period between surgery and the first measurement of CA 19-9 were relatively long (median, 85.5 months). Despite these limitations, this study showed some interesting data. One was the linear relationship with serum calcitonin, as previously demonstrated in a case report by Elisei et al (8). It remains unknown whether and how these two events had any relevance, but this showed the potential use of CA 19-9 for predicting disease prognosis in patients with MTC. One proposed mechanism is perhaps increased expression of CA 19-9 in hypoxia-resistant malignant cells (4). In the current study, patients with MTC who had high serum CA19-9 levels were much more likely to progress and had worse prognosis.
Another important finding was the lack of prognostic significance of the CA19-9 doubling time in this study. The serum calcitonin doubling time has been recognized as a dynamic prognostic factor of MTC in previous studies (1-3), which could be due to its direct association with tumor burden and/or viability of any metastatic lesions. The rapid increase of serum calcitonin level implies the rapid progression of tumors, which is reasonable for prediction of a worse prognosis. However, in this study, the CA19-9 doubling time did not reflect patients' prognoses, suggesting that serum CA19-9 levels may not be directly related to tumor burden or viability of recurrent disease.

In conclusion, serum CA19-9 may be a potential candidate as a prognostic marker of MTC burden and progression. Further studies enrolling larger number of patients and investigation of the mechanism underlying the increased CA19-9 levels in advanced cases are needed to elucidate the clinical significance of this relationship. 
Yasuhiro Ito and

Akira Miyauchi

\section{References}

1. Miyauchi A, Onishi T, Morimoto S, Takai S, Matsuzuka F, Kuma K, Maeda M, Kumahara Y. 1984 Relation of doubling time of plasma calcitonin levels to prognosis and recurrence of medullary thyroid carcinoma. Ann Surg 199:461-466.

2. Ito Y, Miyauchi A, Kihara M, Kudo T, Miya A. 2016 Calcitonin doubling time in medullary thyroid carcinoma after the detection of distant metastases keenly predicts patients' carcinoma death. Endocr J 63:663-667.

3. Miyauchi A, Kudo T, Kihara M, Oda H, Ito Y, Miya A. 2019 Spontaneous deceleration and acceleration of growth rate in medullary thyroid carcinomas suggested by changes in calcitonin doubling times over long-term surveillance. World J Surg 43:504512.

4. Usón Junior PLS, Callegaro-Filho D, Bugano DDG, Moura F, Maluf FC. 2018 Predictive value of serum carbohydrate antigen 19-9 (CA19-9) for early mortality in advanced pancreatic cancer. J Gastrointest Cancer 49:481-486.

5. Galli C, Basso D, Plebani M. 2013 CA 19-9: handle with care. Clin Chem Lab Med 51:1369-1383.
6. Kim HR, Lee CH, Kim YW, Han SK, Shin YS. Yim JJ. 2009 Increased CA19-9 level in patients without malignant disease. Clin Chem Lab Med 47:750-754.

7. Vierbuchen M, Larena A, Schroder S, Hanisch FG, Ortmann M, Larena A. 1992 Blood group antigen expression in medullary carcinoma of the thyroid: an immunohistochemical study on the occurrence of type 1 chain-derived antigens. Virchows Arch B Cell Pathol Incl Mol Pathol 62:79-88.

8. Elisei R, Lorusso L, Romei C, Bottici V, Mazzeo S, Giani C. 2013 Medullary thyroid cancer secreting carbohydrate antigen 19-9 (Ca 19-9): A fatal case report. J Clin Endocrinol Metab 98:3550-3554.

9. Milman S, Whitney KD, Fleischer N. 2013 Metastatic medullary thyroid cancer presenting with elevated levels of CA 19-9 and CA 125. Thyroid 21: 913-916.

10. Alencar R, Kendler DB, Andrade F, Nava C, Bulzico D, de Noronha Pessoa CC, Carbo R, Vaisman F. 2019 CA19-9 as a predictor of worse clinical outcome in medullary thyroid carcinoma. Eur Thyroid J 8:186191. 